\title{
O conceito de bioma
}

\author{
Leopoldo Magno Coutinho ${ }^{1}$
}

Recebido em 12/04/2004. Aceito em 14/06/2005

\begin{abstract}
RESUMO - (O conceito de bioma). O termo fitofisionomia foi proposto praticamente ao mesmo tempo que o termo formação. O termo bioma, proposto mais tarde, apenas adicionou a fauna à uniformidade fitofisionômica e climática, características desta unidade biológica . Várias modificações conceituais foram apresentadas por diversos autores, ao longo do tempo, acrescentando outros fatores ambientais ao conceito original, como o solo, por exemplo. Walter propôs um conceito essencialmente ecológico, considerando bioma como uma área de ambiente uniforme, pertencente a um zonobioma, o qual é definido de acordo com a zona climática em que se encontra. Este conceito considera ainda outros fatores ambientais ecologicamente importantes, como altitude e solo, distinguindo, então, orobiomas e pedobiomas. Um outro fator a ser considerado seria o fogo natural (pirobiomas). Bioma e domínio morfoclimático e fitogeográfico não são sinônimos, uma vez que este último não apresenta necessariamente um ambiente uniforme. O bioma de savana tropical é constituído por um complexo de fitofisionomias, um complexo de formações, representando um gradiente de biomas ecologicamente relacionados, razão suficiente para considerar este complexo como uma unidade biológica.
\end{abstract}

Palavras-chave: formação, bioma, zonobioma, domínio, savana

\begin{abstract}
The biome concept). The terms phytophysiognomy and formation were proposed practically at the same time. The term biome, proposed later, only added the element fauna to the phytophysiognomic and climatic uniformity of the formation concept. Several conceptual modifications have been presented by a number of authors along time, adding other environmental factors to the original concept of biome, as soil for example. Walter proposed an essentially ecological concept, considering biome as an area of uniform environment, belonging to a zonobiome, which is defined by the climatic zone where it is found. This concept takes into consideration other important ecological factors, as altitude and soil, which then constitute orobiomes and pedobiomes. Another factor to be considered is natural fire (pyrobiomes). Biome and morphoclimatic and phytogeographical domain are not synonyms, since the latter does not necessarily have a uniform environment. The tropical savanna biome is a complex of phytophysiognomies, a complex of formations, which represents a gradient of ecologically related biomes, reason enough to consider this complex as a biological unit.
\end{abstract}

Key words: formation, biome, zonobiome, domain, savanna

\section{Introdução}

Com o agravamento dos problemas ambientais em nível global, como as queimadas de florestas na Amazônia, o aumento de gás carbônico na atmosfera e seu conseqüente efeito no aquecimento do Planeta, o crescimento do buraco de ozônio sobre o pólo sul, o avanço das fronteiras agrícolas, em detrimento das áreas naturais e etc., tem aumentado muito o interesse dos pesquisadores e de toda a mídia em denunciar tais fatos e procurar soluções. Hoekstra et al. (2005) ressaltaram que, além de uma "crise de extinção", ao nível de espécies, existe uma crise mais ampla, a "crise dos biomas", muito mais grave, pois, resulta da destruição dos ambientes naturais, onde as espécies surgiram e se desenvolveram. Com a destruição de seus habitats naturais, elas fatalmente desaparecerão.
Segundo o mapa das regiões em crise do mundo que estes autores apresentaram, o Brasil possui grandes áreas em estado crítico ou ameaçadas. Não apenas extinções e destruição de habitats têm sido observadas, mas deslocamentos da distribuição de espécies e de biomas têm sido demonstrados (Peñuelas \& Boada 2003). Simulações com modelos globais da distribuição de tipos funcionais de plantas, variando os valores de certos parâmetros como fotossíntese, evapotranspiração e distribuição das raízes, provocaram modificações na produtividade primária líquida, modificações no balanço competitivo entre tipos funcionais de plantas, ou entre plantas $\mathrm{C}_{3}$ e $\mathrm{C}_{4}$, com uma conseqüente modificação em sua distribuição global. Modificações em parâmetros de evapotranspiração e distribuição de raízes afetaram similarmente a produtividade primária e a umidade do solo, levando

\footnotetext{
1 Universidade de São Paulo, Instituto de Biociências, Departamento de Ecologia, C. Postal 11461, CEP 05422-970, São Paulo, SP, Brasil (leopoldo.magno@terra.com.br)
} 
freqüentemente a modificações no balanço competitivo entre gramíneas e árvores (Hallgren \& Pitman 2000). Todos estes trabalhos mostram quão delicada e susceptível são a existência e a distribuição dos seres vivos em nosso Planeta e quão graves são as modificações que nele estão ocorrendo em função das atividades humanas.

Em termos nacionais, muito se tem escrito sobre a crescente destruição de grandes regiões naturais do país, como a Amazônia, a Mata Atlântica, o Cerrado (quando escrito desta forma, este termo significa "cerrado sensu lato") e outras mais. O emprego de certos termos científicos pelos autores, como a própria "Mata Atlântica", domínio, bioma e outros, tem aparecido com frequiência nos artigos publicados. Todavia, tais termos geralmente não vêm acompanhados dos conceitos que os autores fazem deles, criando, assim, uma grande confusão. Nem sempre seus conceitos coincidem entre si, ou com aqueles empregados nos meios científicos. Alguns autores usam como sinônimos certos termos que conceitualmente são bem distintos. Uma certa uniformidade na conceituação desses termos se faz necessária a fim de que as principais áreas e fatores de risco possam ser estabelecidos para que providências sejam tomadas no sentido de sua conservação.

O presente trabalho tem por objetivo discutir o conceito de um termo muito usado atualmente - bioma investigando sua origem e evolução através dos tempos, até chegar a um conceito mais moderno, destacando-o por sua concepção mais ecológica e prática. Este conceito, conforme desenvolvido por Walter (1986) e adotado no presente trabalho, considera como bioma uma área do espaço geográfico, com dimensões até superiores a um milhão de quilômetros quadrados, representada por um tipo uniforme de ambiente, identificado e classificado de acordo com o macroclima, a fitofisionomia (formação), o solo e a altitude, os principais elementos que caracterizam os diversos ambientes continentais. Uma pequena modificação aqui introduzida foi a recorrência de fogo natural, um outro elemento de importância na determinação de certos ambientes terrestres.

\section{Origem e evolução do conceito}

Ao longo da evolução das plantas vasculares, foram selecionadas diversas "formas de crescimento" (árvores, arbustos, lianas, ervas, epífitas, suculentas e etc.), também consideradas pelos autores modernos como "formas de vida". Ao colonizarem as superfícies emergentes dos oceanos, as plantas formaram diferentes tipos de vegetação. Dependendo do predomínio ou da proporção das diferentes formas de vida que as compunham, bem como de sua densidade, caducidade foliar, entre outras características, essas vegetações apresentaram diferentes estruturas e fitofisionomias (florestas densas, arvoredos ou "woodlands", carrascos, savanas, campos, estepes, desertos e etc.), refletindo, assim, os principais fatores físicos determinantes, como clima, solo, fogo e etc.

A fitofisionomia é a primeira impressão causada pela vegetação (Allen 1998). Segundo Grabherr \& Kojima (1993), a fitofisionomia é uma característica morfológica da comunidade vegetal, sendo Humboldt quem a empregou pela primeira vez para descrever a vegetação. Ainda segundo aqueles mesmos autores, Griesebach propôs o termo "formação" como uma "unidade fisionômica". Segundo o dicionário de Font Quer (1953), Griesebach teria derivado este termo da palavra alemã "Vegetationsform", utilizada por Martius. No Congresso Internacional de Botânica de 1910, realizado em Bruxelas, sua Comissão de Nomenclatura estabeleceu que uma formação "se compõe de associações, que se diferenciam em sua composição florística, mas coincidem, em primeiro lugar, nas condições estacionais e, em segundo lugar, nas suas formas biológicas".

Seguindo seu conceito monoclimácico, Weaver \& Clements (1938) afirmaram: "Each formation is the highest type of vegetation possible under its particular climate, and this relation makes the term climax especially significant, as it is derived from the same root as climate. The formation and climax are identical, and, hence, the same great community may be termed a formation or, for the sake of emphasis, a climax formation".

Holdridge (1947) propôs uma classificação das formações vegetais do mundo por meio de simples dados climáticos, construindo um diagrama triangular onde lança a relação entre a evapotranspiração potencial e a chuva, a precipitação anual e a biotemperatura.

Clements (1949) definiu formação como "The climax community of a natural area in which the essencial climatic relations are similar or identical; that unit of vegetation which is the product of, under the control of, and delimited by, climate". Para este autor, os termos clímax climático e formação são sinônimos. Este é o conceito clementiano de formação.

Com as dúvidas surgidas em relação ao conceito monoclimácico de Clements e a aceitação de um 
conceito policlimácico, outros conceitos de formação surgiram. Para Mueller-Dombois \& Ellenberg (1974) "Plant communities that are dominated by one particular life form, and which recur on similar habitats, are called formations (in the physiognomic-ecological sense). Examples are the tropical rain forest, the mangrove swamp, the cacti desert, the grass steppe,...". Estes autores propõem uma tentativa fisionômico-ecológica de classificação das formações vegetais da Terra, agrupando-as em classes de formações, subclasses, grupos, formações, subformações e outras subdivisões. Eles levam em consideração, portanto, a fisionomia e o habitat.

Para Colinvaux (1993), formação é a vegetação de uma grande região climática, reconhecida por uma forma de vida característica. No Glossário de Ecologia de Watanabe (1997), uma formação vegetal, em seu sentido amplo, é um "tipo de vegetação que ocupa extensa área geográfica, com composição definida de espécies dominantes, clima particular e reconhecida pela fisionomia. Ex. tundra, floresta boreal, cerrado, caatinga do nordeste, floresta amazônica e outras".

Vemos, portanto, que estes novos conceitos já não fazem mais referência à comunidade clímax, como queria Clements (1949). Todavia, o conceito de formação vem sendo atrelado a uma certa área, a um clima definido e à fitofisionomia uniforme da vegetação. A composição florística não participa da conceituação do termo para a totalidade dos autores, exceção feita a Watanabe (1997).

$\mathrm{O}$ termo bioma $($ do grego $\mathrm{Bio}=$ vida $+\mathrm{Oma}=$ grupo ou massa), segundo Colinvaux (1993), foi proposto por Shelford. Segundo Font Quer (1953), este termo teria sido criado por Clements. Em ambos os casos, a diferença fundamental entre formação e bioma foi a inclusão da fauna neste novo termo. Enquanto formação se referia apenas à vegetação, bioma referia-se ao conjunto de vegetação e fauna associada. Talvez por isto certos autores tenham sido levados a considerar bioma e biota como sinônimos (Ferreira, sem data). No glossário do livro de Clements (1949) encontra-se a seguinte definição para bioma: "Biome - A community of plants and animals, usually of the rank of a formation: a biotic community". Ele se caracterizaria pela uniformidade fisionômica do clímax vegetal e pelos animais de maior relevância, possuindo uma constituição biótica característica.

Odum (1971) é de opinião semelhante quanto ao clímax, mas introduziu o substrato físico como componente do conceito, quando afirmou "Regional climates interact with regional biota and substract to produce large, easily recognizable community units, called biomes...In a given biome the life form of the climatic climax vegetation... is uniform."

Whittaker (1971) definiu bioma como "A major kind of community, conceived in terms of physiognomy, on a given continent, is a biome or formation. (Formation is used when the concern is with plant communities only, biome when the concern is with both plants and animals...)...we have to use both structure and environment when we define biomes." Parece que este autor limitou a abrangência do termo bioma a um continente. Cada continente teria, então, seus próprios biomas. Fisionomia, estrutura e ambiente devem ser considerados ao se definir um bioma.

Clapham (1973) disse textualmente: "The distribution of the biomes is ultimately controlled by the abiotic factors of the environment - specially climate - and a given biome may be formed in several different parts of the world", contrariando, assim, a idéia anterior.

Dajoz (1973) assim se referiu ao termo bioma: "Os biomas são também chamados por diversos autores formações ou complexos. O bioma é um agrupamento de fisionomia homogênea $e$ independente da composição florística. Estende-se por uma área bastante grande e sua existência é controlada pelo macroclima...Na comunidade terrestre os biomas correspondem às principais formações vegetais naturais." Importante notar que seu conceito de bioma independe da florística da vegetação, mas apenas de sua fisionomia. Um mesmo tipo de bioma pode ter floras diferentes. Grande similaridade florística entre duas comunidades não significa que pertençam a um mesmo tipo de bioma.

Segundo Whitaker (1978), “A community-type on a given continent defined by growth-form dominance (and major features of environment) is a formation. A grouping of similar formations occurring in similar climates of the different continents is a formation-type... Ecologists concerned with animals as well as plants have often used as corresponding units the biome and biometype." O bioma teria, então, dimensões subcontinentais e o bioma-tipo seria a soma de todos os biomas de um determinado tipo, nos diversos continentes (o cerrado sensu lato - chamado por muitos de "a savana brasileira" - seria um bioma, enquanto as savanas do mundo constituiriam o bioma-tipo). 
Concordando com Dajoz (1973), Crawley (1989) afirmou que: "The great biomes of the world show a remarkable degree of convergence in their physiognomy, despite wide differences in the taxonomic affinities of their floras... rain forest of Brazil resembles rain forest in south east Asia...".

Para Cox \& Moore (1993), "One frequently used level of scale at which the ecosystem concept is applied in biogeography is that of the biome, or formation. ... The classification of the living world using this biogeographical, rather than a taxonomic, approach is particularly useful because it allows the development of general statements concerning the function and the future of these units ... Although the tropical savanna grasslands of Brazil, Kenya, India and Thailand comprise different plant and animal species, they have much in common in terms of their architecture, seasonal growth and productivity, life forms of animals and plants, and the ways in which they have been used by human population. Management practice are similar in different geographic areas, hence much that can be learned from one region can be applied to another."

Ao contrário de outros autores modernos, Allen \& Hoekstra (1992) afirmam textualmente "The biome is defined primarily by its biota." Todavia, alguns anos mais tarde, Allen (1998) altera sua opinião ao dizer: "Biomes differ from communities in that biomes are not conceived as being composed of species... Of course biomes contain species, but species are not the category used to group plants as they are found in biomes. Biomes are identified by the dominant life form... Because life form looks so distinctive, biomes are recognizable by how they look on first glance. The first impression of vegetation is called vegetational physiognomy.". Portanto, é a fitofisionomia que nos permite reconhecer os diferentes biomas.

Colinvaux (1993) definiu bioma como um "ecosystem of a large geographic area in which plants are of one formation and for which climate sets the limits". Importante salientar que se trata, pois, de um ecossistema, de uma unidade ecológica, estrutural e funcional, com seus componentes bióticos e abióticos. Todavia, não se deve supor erroneamente que bioma e ecossistema sejam sinônimos. Para a fisionomia, elemento de fundamental importância na classificação dos biomas, a fauna tem pouco ou nenhum significado. O mesmo não ocorre quando nos referimos a um ecossistema.

\section{O conceito de Walter e sua classificação dos biomas}

Intencionalmente deixou-se para discutir este conceito por último. Isto porque ele pode ser considerado como um dos mais modernos e de concepção mais ecológica e prática, razão pela qual o autor o adota.

Baseando-se no trabalho de Gaussen (1954; 1955), Walter \& Lieth (1960) elaboraram um tipo especial de diagrama ecológico de clima e publicaram um Atlas Mundial de Diagramas Climáticos, classificando os climas do mundo em nove Zonas Climáticas, distribuídas praticamente como faixas ou zonas latitudinais da Terra, que vão do equador aos pólos. Como o macroclima é de fundamental importância para a vegetação, cada uma dessas faixas representa uma grande unidade ecológica da geobiosfera, denominada Zonobioma e classificadas de acordo com a Tab. 1.

Finalmente os autores reconheceram um décimo tipo climático, que corresponde ao clima de montanha ou de altitude, podendo ocorrer nos diversos Zonobiomas. ${ }^{1}$

Os Zonobiomas têm grandes dimensões, distribuindo-se pelo globo terrestre através dos continentes. Já os domínios morfoclimáticos e fitogeográficos de Ab'Saber (1977) têm dimensões subcontinentais, de milhões até centenas de milhares de quilômetros quadrados (Watanabe 1997). Os biomas podem restringir-se a pequenas áreas ou chegar até mais de 1 milhão de quilômetros quadrados (Walter 1986). Um mesmo tipo de bioma é representado por uma ou mais áreas, distintas geograficamente, constituindo, cada qual, uma unidade daquele tipo de bioma.

Os biomas característicos de cada Zonobioma são chamados simplesmente de biomas ou eubiomas. Quando eles não correspondem, ou não refletem a zona climática em que se encontram, sendo co-determinados por algum outro fator ambiental, como altitude ou solo, eles são chamados, respectivamente, de orobiomas ou pedobiomas, seguidos pelo número romano das suas zonas climáticas respectivas (orobioma I, orobioma II, pedobioma I, pedobioma II etc.).

Os orobiomas geralmente apresentam uma sequiência típica de faixas altitudinais, que Walter (1986)

\footnotetext{
1 Veja-se Walter (1986), porém com atenção à página 21, que contém algumas imperfeições de impressão, confundindo os diversos biomas. Veja-se também Walter $(1971 ; 1973)$ e Walter et al. (1975).
} 
Tabela 1. Classificação dos Zonobiomas de Walter (1986) com seus respectivos climas e tipos de vegetação zonal.

\begin{tabular}{cll}
\hline Zonobioma & Clima & Vegetação Zonal \\
\hline I & $\begin{array}{l}\text { Equatorial, úmido e quente, cujas variações térmicas } \\
\text { maiores ocorrem dentro de períodos diários }\end{array}$ & Florestas pluviais tropicais sempre verdes \\
II & Tropical, com chuvas de verão e inverno seco & Florestas tropicais estacionais ou savanas \\
III & Subtropical árido & Desertos quentes \\
IV & Mediterrâneo, com chuvas de inverno e verão seco & Vegetação esclerófila (chaparral, maqui) \\
V & Quente-temperado sempre úmido & Florestas subtropicais sempre verdes \\
VI & Temperado úmido, com inverno curto & Florestas temperadas caducifólias \\
VII & Temperado árido & Estepes ou desertos com inverno frio \\
VIII & Boreal & Florestas de coníferas (Taiga) \\
IX & Polar & Tundras \\
\hline
\end{tabular}

chamou de colinosa, montana, alpina e niveal. Esta sequiência é também conhecida como baixomontana, submontana, montana e altimontana. Além disto, ele distinguiu orobiomas uni, inter e multizonais, dependendo de eles estarem incluídos num só zonobioma, de formarem uma fronteira entre dois zonobiomas ou de estenderem-se por dois ou mais zonobiomas.

Dependendo do fator pedológico em questão, pode-se falar mais explicitamente em litobioma I, II, III, IV etc. (quando o solo é pedregoso), ou psamobioma I, II, III etc. (quando o solo é arenoso), ou halobioma I, II, III etc. (quando o solo é salino), ou helobioma I, II, III etc. (quando o solo é encharcado, brejoso ou pantanoso), ou hidrobioma I, II, III etc. (quando o solo é coberto por água), ou peinobioma I, II, III etc. (quando o solo é muito pobre, carente de nutrientes). Embora o autor não tenha mencionado, o fogo natural pode ser um outro fator co-determinante e, nesse caso, usar-se-ia o termo pirobioma I, II, III etc. Esse fator sempre atuou junto às savanas tropicais, sendo responsável pela seleção de muitas de suas características eco-fisiológicas, morfo-anatômicas e fisionômico-estruturais.

Para Walter (1986), “Um bioma, como ambiente, é uma área uniforme pertencente a um zonobioma, orobioma ou pedobioma." Considerado como um ambiente, este conceito é fundamentalmente ecológico, levando em consideração não apenas o clima, mas também a altitude e as características do solo. Ele considera todo o ecossistema. Além disto, este conceito permite classificar e identificar o tipo de bioma, uma vez que o próprio nome do bioma em questão já indica o tipo de ambiente, inclusive quais os seus principais determinantes.

Comparando-se os tipos, o número e a distribuição dos principais biomas do mundo, de acordo com diversos autores, como Odum (1959), Kormondy (1969), Walter (1986), Colinvaux (1993), Cox \& Moore (1993), Olson et al. (2001), vê-se que existe uma grande concordância entre eles (Tab. 2), com algumas diferenças em detalhes da distribuição, o que pode ser explicado em função da pequena escala dos mapas apresentados. As maiores discrepâncias ocorrem na América do Sul, por certo menos conhecida pelos autores. No caso de Walter (1986), eles correspondem aos Zonobiomas (ou biomas zonais). Considerando-se também os pedobiomas e os orobiomas, o sistema de Walter (1986) ultrapassa, em número, até mesmo os catorze tipos reconhecidos por Olson et al. (2001). Estes autores reconheceram não apenas os grandes biomas da maioria dos autores, que geralmente são determinados pelo clima, mas alguns outros, determinados pelas condições ambientais, como manguezais, campos e savanas inundáveis. Neste sentido eles se aproximam um pouco do conceito de Walter (1986).

Infelizmente, faltam estudos mais detalhados, principalmente aqueles de natureza ambiental, ecológica, para muitos dos biomas brasileiros, que venham a permitir classificação e identificação mais seguras, embasadas em dados científicos. Muitos dos estudos fitossociológicos realizados em tais biomas trariam uma enorme contribuição, neste sentido, se fossem complementados por dados sobre o clima, os solos e outras características do ambiente físico. Algum 
Tabela 2. Comparação dos sistemas de classificação dos tipos de biomas do mundo, segundo diversos autores. $\mathrm{Fl}=\mathrm{floresta}$; $\mathrm{Tr}=\mathrm{tropical}$; $\mathrm{Pl}=$ pluvial; $\mathrm{STr}=$ subtropical; Dec = decídua; Est = estacional; SVerd = sempre verde; Temp = temperada; Lat = latifoliada; Sav = savana; Escr $=$ escrube; Woodl $=$ woodland Medit $=$ mediterrâneo

\begin{tabular}{|c|c|c|c|}
\hline $\begin{array}{l}\text { Odum (1959) } \\
\text { Kormondy (1969) }\end{array}$ & Walter (1986) & $\begin{array}{l}\text { Cox \& Moore (1993) } \\
\text { Colinvaux (1993) }\end{array}$ & Olson et al. (2001) \\
\hline $\begin{array}{l}\text { Fl. Tr. Pl. } \\
\text { Fl. Tr. Dec. } \\
\text { Sav. e Campo Tr. } \\
\text { Deserto } \\
\text { Chaparral } \\
\text { Escr. Tr. } \\
\text { Fl. Temp. Dec. e Pl. } \\
\text { Campo Temp. } \\
\text { Fl. Boreal (Taiga) } \\
\text { Tundra } \\
\text { Montanhas }\end{array}$ & $\begin{array}{l}\text { ZB I Fl. Tr. Pl. } \\
\text { ZB II Fl. Tr. Dec. } \\
\text { ZB II Sav. Tr. } \\
\text { ZB III Deserto STr. } \\
\text { ZB IV Chaparral } \\
\text { ZB V Fl. Quente Temp. SVerd. } \\
\text { ZB VI Fl. Temp. Dec. } \\
\text { ZB VII Estepe } \\
\text { ZB VII Deserto Temp. } \\
\text { ZB VIII Fl. Boreal (Taiga) } \\
\text { ZB IX Tundra } \\
\text { Orobiomas (I a IX) } \\
\text { Pedobiomas (I a IX) }\end{array}$ & $\begin{array}{l}\text { Fl. Tr. Pl. } \\
\text { Fl. Tr. Est. } \\
\text { Sav., Campo e Escr. Tr. } \\
\text { Deserto } \\
\text { Chaparral } \\
\text { Fl. Temp. } \\
\text { Campo Temp. } \\
\text { Fl. Boreal (Taiga) } \\
\text { Tundra } \\
\text { Montanhas }\end{array}$ & $\begin{array}{l}\text { Fl. Tr. e STr. Úmidas } \\
\text { Fl. Tr. e STr. Secas } \\
\text { Fl. Tr. e STr. de coníferas } \\
\text { Fl. Temp. Lat. e Mista } \\
\text { Fl. Temp. de coníferas } \\
\text { Fl. Boreal (Taiga) } \\
\text { Sav., Campo e Escr. Tr. e STr. } \\
\text { Sav., Campo e Escr. Temp. } \\
\text { Sav. e Campo inundável } \\
\text { Sav. e Campo montano } \\
\text { Tundra } \\
\text { Fl., Woodl. e Escr. Medit. } \\
\text { Deserto e Escr. Xéricos } \\
\text { Manguezal }\end{array}$ \\
\hline
\end{tabular}

tempo a mais de esforço de trabalho ampliaria enormemente os conhecimentos a respeito daqueles biomas, possibilitando estabelecer quais os principais fatores determinantes daqueles tipos de ambiente. A diversidade em termos de biomas merece tanto interesse, estudo e admiração, quanto a diversidade em termos de espécies.

\section{Alguns exemplos de biomas no Brasil}

Tendo em vista a bibliografia referida até aqui, considera-se que um bioma é uma área do espaço geográfico, com dimensões de até mais de um milhão de quilômetros quadrados, que tem por características a uniformidade de um macroclima definido, de uma determinada fitofisionomia ou formação vegetal, de uma fauna e outros organismos vivos associados, e de outras condições ambientais, como a altitude, o solo, alagamentos, o fogo, a salinidade, entre outros. Estas características todas lhe conferem uma estrutura e uma funcionalidade peculiares, uma ecologia própria.

Para dar alguns exemplos, pode-se começar por aqueles biomas que compõem o domínio morfoclimático e fitogeográfico amazônico. Ao contrário do senso comum, este não é constituído por um único tipo de floresta, por um único bioma, em toda sua vastíssima extensão. Ali existem diferentes tipos de biomas, como a floresta de terra-firme, um bioma de floresta tropical pluvial do Zonobioma I, que predomina; a floresta de igapó, inundável, um bioma de floresta pluvial tropical do hidrobioma I; as caatingas do Rio Negro, um bioma de savana arenosa, distrófica, inundável do psamopeino-hidrobioma I; os campos rupestres, como os dos picos das serras, nas fronteiras com países vizinhos, um litobioma do Orobioma I, e etc. O domínio amazônico não é, portanto, um bioma único. Ele é um mosaico de biomas.

No domínio atlântico, encontra-se a Mata Atlântica, também chamada de "mata de encosta", um outro bioma de floresta tropical pluvial do Zonobioma I; a floresta de restinga inundável, um bioma de floresta tropical pluvial do psamo-hidrobioma I; a floresta de restinga não inundável, um bioma de floresta tropical pluvial do psamobioma I; os manguezais, um bioma de floresta tropical pluvial, paludosa, marítima do helohalobioma I; os campos de altitude, geralmente acima de dois mil metros sobre o nível do mar, um bioma campestre do Orobioma I; as formações rupestres sobre afloramentos rochosos dos picos das serras, um bioma desse tipo de formação, do litobioma I ou litoorobioma I. Também aqui encontra-se um mosaico de biomas, como mostraram Porembski et al. (1998) e Scarano (2002).

Outros exemplos de biomas, agora pertencentes ao domínio do cerrado, seriam o cerrado sensu lato (Cerrado), um bioma de savana do piro-peinobioma II; as florestas de galeria, um bioma de floresta tropical estacional, sempre verde, paludosa, do hidro-helobioma II; os campos paludosos, um bioma campestre tropical do helobioma II; os campos rupestres da Serra do 
Espinhaço, conhecidos pela sua alta biodiversidade e riqueza em endemismos, que seriam um bioma savânico do lito-piro-peinobioma II; as florestas tropicais estacionais sempre verdes, um bioma desse tipo de florestas do Zonobioma II; as florestas tropicais estacionais semidecíduas, um bioma desse outro tipo de florestas do pedobioma II; as florestas tropicais estacionais decíduas, um bioma desse tipo de florestas do litobioma II, características de solos rasos ou afloramentos de calcário. Embora o macroclima seja o mesmo, tropical com chuvas de verão e inverno seco, encontram-se aí vários biomas distintos. São fitofisionomias, formações, bastante diversas. Seus solos, do ponto de vista fisico-químico, hídrico, biológico, também são muito diferentes. A ocorrência de queimadas, um fator natural, varia muito de frequiência nestes diversos ambientes. Não se deve duvidar em considerá-los como biomas individuais, que fazem parte de um mesmo domínio morfoclimático e fitogeográfico. Por sua vez, este é, também, um mosaico de diferentes biomas, uns mais extensos, outros menos. O mais extenso, que predomina ao longo da vastidão do domínio, deu-lhe o nome - o domínio do cerrado.

O bioma Cerrado merece aqui uma discussão um pouco mais longa. No conceito de Coutinho (1978), o cerrado sensu lato não tem uma fisionomia única e uniforme, mas sim três: a campestre (campo limpo de Cerrado), a savânica (campo sujo de Cerrado, campo cerrado e cerrado sensu stricto) e a florestal (cerradão), constituída por florestas tropicais estacionais escleromorfas semidecíduas mais abertas, arvoredos ou "woodlands" (savana florestada). O Cerrado seria, portanto, um complexo de biomas, distribuídos em mosaico.

Modernamente, o Cerrado é considerado como sendo uma savana. Este termo aceita dois conceitos: um de natureza meramente fitofisionômica e outro referente a um grande tipo de ecossistema, com seu tipo particular de vegetação. Segundo Adámoli \& Azevedo (1983, apud Goedert 1987), a fisionomia savânica ocupa 67\% da área do Cerrado, dando unidade geográfica à região. Os campos cerrados, os campos sujos e os campos limpos, não incluídos na fisionomia savânica, perfazem $12 \%$. Os cerradões cobrem $10 \%$. Adicionando os campos cerrados e os campos sujos à fisionomia savânica, já se chega a mais de $70 \%$, talvez próximo aos $80 \%$. Este amplo predomínio da fisionomia savânica, justificaria considerar-se o Cerrado como um bioma de savana, do ponto de vista fitofisionômico. Caso se queira ser absolutamente fiel ao conceito de bioma adotado pelos diversos autores mencionados adrede, pode-se dizer que o Cerrado não é um bioma único, mas um complexo de biomas, formado por um mosaico de comunidades pertencentes a um gradiente de formações ecologicamente relacionadas, que vai de campo limpo a cerradão. Todavia, a grande maioria dos autores nacionais e internacionais, aceita o Cerrado como sendo um bioma de savana. Goedert (l.c.) diz: "Cerrados: as savanas do Brasil". No "Vocabulário Básico de Recursos Naturais e Meio Ambiente" do IBGE (2004) chega-se ao extremo de definir savana como "Vegetação xeromorfa preferencialmente de clima estacional, com aproximadamente seis meses secos, não obstante poder ser encontrada também em clima ombrófilo. Reveste solos lixiviados aluminizados, apresentando sinúsias de hemicriptófitos, geófitos e fanerófitos oligotróficos de pequeno porte com ocorrência em toda a zona Neotropical. É dividida em: Savana florestada (cerradão), Savana arborizada (campo cerrado), Savana parque e Savana gramíneo-lenhosa. Cerrado.”. Esta definição faz o leitor supor que o único bioma de savana neotropical seja o Cerrado, esquecendo-se, por exemplo, dos Lhanos venezuelanos, da caatinga nordestina, da caatinga amazônica do Rio Negro. Omite-se também com relação a outros biomas de savana de ocorrência nas zonas paleotropical e australiana, não conhecidos pelo nome de Cerrado.

Para certos autores, principalmente da África e da Austrália (Huntley 1982; Huntley \& Walker 1982; Walker \& Gillison 1982), o termo savana não tem um significado meramente fitofisionômico, mas refere-se a um tipo de ecossistema de grande escala, isto é, "those ecosystems which lie between the equatorial rainforests and the deserts and semi-deserts of Africa, Australia and South America. These savannas form a continuum of physiognomic types ranging from closed woodlands with a heliophytic grass understorey, through open savanna woodlands to treeless edaphic grasslands. In all areas Kranz syndrome or $C_{4}$ grasses dominate the herbaceous layer while the woody component, at the moist end of the moisture gradient, comprises fire tolerant trees and shrubs." O conceito de savana acima não incluiria, ao contrário do que afirmou Eiten (1990), florestas fechadas, densas, como as florestas tropicais estacionais e cerradões densos e sombrios. Os "closed woodlands" a que se referiram corresponderiam aos cerradões pouco mais abertos, onde ainda há ocorrência de fogo e cujas árvores são tolerantes a ele. Aliás, o termo "woodland", ou arvoredo, é até usado por certos autores para a 
fitofisionomia de cerradão (Eiten 1972; 1983; 2001; Goodland 1971). Tais "closed woodlands" não correspondem aos cerradões fechados, nem às florestas tropicais estacionais densas e exuberantes, cujas espécies não toleram fogo e exigem solos mais ricos em nutrientes. Além disso, essas formações fechadas, com dossel contínuo, criam muita sombra em seu interior, o que impede o desenvolvimento de um estrato herbáceo-subarbustivo heliófilo, característica fundamental do bioma de savana. A mudança deste estrato, de heliófilo para umbrófilo estabelece o exato limite entre o bioma de savana e os biomas de florestas tropicais estacionais densas vizinhos.

$\mathrm{O}$ fato dos cerradões densos e fechados conterem espécies de cerrado, não deve ser critério para incluílos no bioma savânico do Cerrado, uma vez que a flora não deve ser levada em conta, segundo os conceitos de bioma dos principais autores internacionais, como já se salientou atrás. Pode significar, isto sim, que pertençam todos a uma mesma província florística. Eles já estão fora dos limites fisionômicos e ambientais deste bioma. Neles já não existe um estrato herbáceo heliófilo, já não há mais ocorrência de fogo, distinguindo-se fisionômica e funcionalmente. Tais cerradões representam transições entre o bioma de savana do Cerrado e o bioma da floresta tropical estacional semicaducifólia.

Todas as savanas tropicais do mundo, nos mais diferentes continentes, têm essa complexidade fitofisionômica, formam esse mosaico, esse gradiente de comunidades fisionomicamente diversas, e, no entanto, são consideradas como um bioma pela grande maioria dos autores. É que as comunidades que formam esse gradiente são ecologicamente relacionadas, têm os mesmos fatores determinantes ou co-determinantes e respondem a seus gradientes. Os mapas de distribuição dos biomas no mundo colocam o Cerrado brasileiro e as caatingas nordestinas exatamente na área correspondente aos biomas do tipo savana (Odum 1959; Walter 1986; Kormondy 1969; Kreeb 1983; Watanabe 1997). Walter (1986) considerou o Cerrado como uma "savana especial", ao lado dos Lhanos do Orinoco, na Venezuela, das savanas australianas e das savanas da África Oriental (região do Serengeti). Portanto, ao se considerar o Cerrado como um bioma de savana, do ponto de vista de grande tipo de ecossistema, não se foge ao conceito da grande maioria dos autores internacionais. $\mathrm{O}$ Cerrado deve ser considerado um bioma de savana, quer do ponto vista fitofisionômico, quer do ponto de vista ecossistêmico.
As outras fitofisionomias do domínio do cerrado, como as matas de galeria sempre verdes, os campos paludosos, as florestas tropicais estacionais sempre verdes, as semicaducifólias e as caducifólias, também chamadas de matas secas (Eiten 1990; Ribeiro \& Walter 1998), estão fora do bioma de savana do Cerrado, ao contrário do que consideram certos autores, como Ribeiro \& Walter (1998), Oliveira-Filho \& Ratter (2002). Estas são florestas de maior porte, de maior complexidade estrutural, de estrato herbáceo ombrófilo, de troncos mais retilíneos e de maior diâmetro, cortiças delgadas, folhas pouco ou nada esclerificadas, fauna de sombra, solos mesotróficos a eutróficos, mais argilosos e com maior retenção hídrica, fogo natural ausente ou pontual, ou apenas de serapilheira, nas bordas de mata em contato com Cerrados queimados. Uma boa evidência da distinção destas florestas em relação ao Cerrado é o seu quase desaparecimento causado pelo homem, à procura de madeiras de lei e de solos naturalmente férteis, próprios para a agricultura e a pecuária. Embora empiricamente, até o caboclo percebeu, no passado, esta diferença. Só bem mais recentemente, com o uso de técnicas agrícolas modernas, é que se passou a usar o bioma de savana do Cerrado para aqueles fins. O domínio do cerrado compreende, portanto, distintos biomas. Não são apenas fitofisionomias de um mesmo bioma. As diferenças entre estes ecossistemas vão muito além. Conferem-lhes o caráter de biomas próprios. O bioma é um tipo de ambiente bem mais uniforme em suas características gerais, em seus processos ecológicos, enquanto que o domínio é muito mais heterogêneo. Bioma e domínio não são, pois, sinônimos. Usá-los como sinônimos é particularmente perigoso para a preservação e conservação das matas de galeria, matas tropicais estacionais sempre verdes, semicaducifólias ou caducifólias e outros biomas, pois as considera como partes integrantes do "bioma do cerrado" que, pela Constituição de 1988 , não é considerado "patrimônio nacional". E esta é a Lei Maior que subjuga todas as demais legislações florestais eventualmente existentes. Isto legalizaria a derrubada dessas florestas, já em extinção, para fins agropastoris. Só se pode entender esta sinonímia como conceitos políticos, ou político-conservacionistas, da mesma forma como o são os conceitos de Amazônia Legal, Polígono das Secas, Mata Atlântica (segundo o CONAMA). Tais conceitos não são, todavia, conceitos científicos.

A caatinga nordestina sensu lato, é um bioma de savana semi-árida do Zonobioma II, com temperaturas mais elevadas e acentuada evapotranspiração potencial, 
o que agrava ainda mais os efeitos da baixa e irregular pluviosidade. Assemelha-se ao bioma de savana do Cerrado, sendo também formada por um complexo de formas fisionômicas distribuídas em mosaico, como caatinga arbórea, caatinga arbustiva, caatinga espinhosa etc. (vejam-se os trabalhos de AndradeLima $(1966 ; 1981)$, que muito acertadamente reconheceu, dentro do domínio da caatinga, outras formações, que não considerou como sendo de caatinga). Pode-se considerá-la como savana semiárida, em contraste com a savana úmida do Cerrado, à semelhança do que ocorre na África. Algumas de suas áreas mais secas e mais quentes são consideradas por Walter \& Lieth (1960) como um zonoecótono entre os Zonobiomas I e III (região do Seridó). Aquele bioma predomina dentro do domínio que leva o seu nome, compondo-o juntamente com o bioma de florestas tropicais ombrófilas sempre verdes (Zonobioma I), por exemplo, como as que ocorrem nos brejos de altitude. Acresçam-se, ainda, os carnaubais, que acompanham as margens dos rios e suas desembocaduras, um bioma florestal do hidro-helobioma II, com clima semi-árido, como o da caatinga.

As florestas de pinheiro-do-paraná (florestas mistas de araucária e dicotiledôneas) constituem um bioma de florestas subtropicais-temperadas, sempre verdes, do zonoecótono entre os Zonobiomas V eVI, ocorrendo em áreas com maior freqüência de temperaturas negativas no inverno, inclusive pequenas nevascas em alguns locais.

Os campos sulinos, do domínio das pradarias, são, muito provavelmente, um bioma campestre do pedopirobioma $\mathrm{V}$ (na zona climática $\mathrm{V}$, quente-temperada sempre úmida, o esperado seriam florestas subtropicais densas sempre verdes; a existência de campos deve estar relacionada a fatores pedológicos e a fogo). Não parece adequado considerá-los como savanas estépicas ou estepes, conforme consta do Mapa de Vegetação do Brasil (IBGE 1993), elaborado de acordo com o sistema de Veloso \& Góes-Filho (1982), as quais corresponderiam ao Zonobioma VII, de clima temperado árido. A mesma observação pode-se fazer com relação à caatinga nordestina (savana tropical semiárida do Zonobioma II).

O Pantanal matogrossense é constituído por um complexo ou mosaico de diferentes biomas florestais de hidrobiomas e helobiomas (carandazais, paratudais), savânicos de piro-peinobiomas (cerrados das cordilheiras entre lagoas), florestais de litobiomas (florestas tropicais estacionais caducifólias sobre afloramentos rochosos e solos rasos), campestres de hidro-helobiomas (campos inundáveis), em meio a rios, lagoas de água doce (baias), lagoas de água salobra e alcalina (salinas) etc., todos pertencentes ao Zonobioma II. Muitas de suas comunidades encontram-se em plena sucessão hidrarca, dentro desse grande espaço da hidrobiosfera, em transição para a geobiosfera. Ao contrário da savana, aqui as comunidades em mosaico não formam, em geral, um gradiente de comunidades ecologicamente relacionadas.

A classificação dos biomas brasileiros que aqui se apresenta concorda razoavelmente com o Mapa de Vegetação do Brasil (IBGE 1993) e com o sistema de classificação de Veloso \& Góes-Filho (1982), muito utilizado atualmente, ressalvado o uso do termo estepe para a caatinga do nordeste e os campos sulinos. Estes autores, como Andrade-Lima (1966) e Rizzini (1997), não fizeram uso do termo bioma, mas formação, uma vez que se referem apenas à vegetação. Este último autor considerou os termos formação e bioma como equivalentes e classifica a vegetação brasileira em "complexos de formações", os quais incluem diferentes tipos de biomas. Tais complexos corresponderiam, de certa forma, aos domínios de Ab'Saber (1977).

O grande número de biomas existente no território brasileiro não deve causar estranheza ou espanto ao leitor. A grande biodiversidade tropical não se limita apenas às espécies, mas estende-se também às fitofisionomias, às formações, aos ambientes de vida e, conseqüentemente, aos biomas. Essa é mais uma riqueza que o Brasil possui.

\section{Agradecimentos}

Aos colegas do Departamento de Ecologia do Instituto de Biociências da USP: Dra. Marico Meguro, Dra. Vânia Regina Pivello, Dr. Waldir Mantovani e Dr. Welington Braz Carvalho Delitti, agradeço pelas valiosas críticas e sugestões.

\section{Referências bibliográficas}

Ab'Saber, A.N. 1977. Os domínios morfoclimáticos da América do Sul. Geomorfologia, Universidade de São Paulo 52: 1-22.

Adámoli, J. \& Azevedo, L.G. 1983. Regionalização dos Cerrados: parâmetros quantitativos.

Allen, T.F.H. 1998. Community Ecology. Pp. 315-383. In: S.I. Dodson; N.E. Langston; M.G. Turner; S.R. Carpenter; J.F. Kitchell; R.L. Jeanne; A.R. Ives \& T.F.H. Allen, (Contrib.). Ecology. Oxford University Press Inc. Oxford.

Allen, T.F.H. \& Hoekstra, T.W. 1992. Toward a unified ecology. Columbia University Press. 
Andrade-Lima, D. 1966. Vegetação. In: Atlas Nacional do Brasil. IBGE/Conselho Nacional de Geografia.

Andrade-Lima, D. 1981. The caatingas dominium. Revista Brasileira de Botânica 4: 149-153.

Clapham Jr., W.B. 1973. Natural Ecosystems. New York, McMillan.

Clements, F.E. 1949. Dynamics of Vegetation. New York, The H.W. Wilson Co.

Colinvaux, P. 1993. Ecology 2. New York, John Wiley \& Sons, Inc.

Coutinho, L.M. 1978. O conceito de cerrado. Revista Brasileira de Botânica 1: 17-23.

Cox, C.B. \& Moore, P.D. 1993. Biogeography: an ecological and evolutionary approach. Fifth Edition. London, Blackwell Scientific Publications.

Crawley, M.J. 1989. The Structure of Plant Communities. Pp. 1-496. In: M.J. Crawley (ed.). Plant Ecology. Oxford, Blackwell Science.

Dajoz, R. 1973. Ecologia Geral. Rio de Janeiro, Ed. Vozes.

Eiten, G. 1972. The cerrado vegetation of Brazil. The Botanical Review 38: 201-341.

Eiten, G. 1983. Classificação da vegetação do Brasil. Brasília, CNPq.

Eiten, G. 1990. Vegetação do cerrado. Pp. 9-65. In: M.N. Pinto (org.). Cerrado - caracterização, ocupação e perspectivas. Brasília, Editora UnB.

Eiten, G. 2001. Vegetação Natural do Distrito Federal. Brasília, Editora UnB. Edição Sebrae.

Ferreira, A.B.H. (sem data). Novo Dicionário da Língua Portuguesa. $1^{\mathrm{a}}$ edição; $11^{\mathrm{a}}$ impressão. Rio de Janeiro, Editora Nova Fronteira.

Font Quer, P. 1953. Diccionario de Botánica. Barcelona, Editorial Labor.

Gaussen, H. 1954. Théorie et classification des climats et microclimats. 8me. Congr. Internat. Bot. Paris, Sect. 7 et 3: $125-130$

Gaussen, H. 1955. Expression des milieux par des formules écologiques; leur représentation cartographique. Colloques Internationaux du Centre Naturel de Recherche Scientifique 59: 257-269.

Goedert, W.J. 1987. Solos dos Cerrados. Tecnologias e estratégias de manejo. Brasília, Nobel, São Paulo e Embrapa.

Goodland, R.J.A. 1971. A physiognomic analysis of the "cerrado vegetation" of Central Brazil. Journal of Ecology 59: 411-419.

Grabherr, G. \& Kojima, S. 1993. Vegetation Diversity and Classification Systems. Pp. 218-232. In: A.M. Solomon \& H.H. Shugart (eds.). Vegetation Dynamics \& Global Change. New York, Chapman \& Hall.

Hallgren, W.S. \& Pitman. 2000. The uncertainty in simulations by a Global Biome Model (BIOME 3) to alternative parameter values. Global Change Biology 6: 483-495.

Holdridge, I.R. 1947. Determination of world plant formations from simple climatic data. Science 105: 367-368.

Huntley, B.J. 1982. Southern African Savannas. In: B.J. Huntley \& B.H. Walker (eds.). Ecology of Tropical Savannas. Ecological Studies 42: 101-119.
Huntley, B.J. \& Walker, B.H. (eds.). 1982. Introduction. Ecology of Tropical Savannas. Ecological Studies 42: $1-2$.

IBGE. 1993. Mapa de Vegetação do Brasil. Ministério do Planejamento e Orçamento.

IBGE. 2004. Vocabulário Básico de Recursos Naturais e Meio Ambiente. $2^{\mathrm{a}}$ ed. Rio de Janeiro, Instituto brasileiro de Geografia e Estatística.

Kormondy, E.J. 1969. Concepts of Ecology. New Jersey, Prentice-Hall Inc.

Kreeb, K. 1983. Vegetationskunde. Stuttgart, Verlag Eugen Ulmer.

Mueller-Dombois, D. \& Ellenberg, H. 1974. Aims and Methods of Vegetation Ecology. New York, John Wiley \& Sons, Inc.

Odum, E. 1959. Fundamentals of Ecology. Philadelphia, W.B. Saunders Co.

Odum, E. 1971. Fundamentals of Ecology. London, W.B. Saunders Co.

Oliveira-Filho, A.T. \& Ratter, J.A. 2002. Vegetation Physiognomies and Woody Flora of the Cerrado Biome. Pp. 91-120. In: P.S. Oliveira \& R.J. Marquis (eds.). The Cerrados of Brazil. New York, Columbia University Press.

Olson, D.M.; Dinerstein, E.; Wikramanayake, E.D.; Burgess, N.D.; Powell, G.V.N.; Underwood, E.C.; D'Amico, J.A.; Itoua, I.; Strand, H.E.; Morrison, J.C.; Loucks, C.J.; Allnutt, T.F.; Ricketts, T.H.; Kura, Y.; Lamoreux, J.F.; Wetengel, W.W.; Hedao, P. \& Kassem, K.R. 2001. Terrestrial Ecoregions of the World: A New Map of Life on Earth. Bioscience 51: 933-938.

Peñuelas, J. \& Boada, M. 2003. A global change-induced biome shift in the Montseny mountains (NE Spain). Global Change Biology 9: 131-140.

Porembski, S.; Martinelli, G.; Ohlemuller, R. \& Barthlott, W. 1998. Diversity and ecology of saxicolous vegetation mats on the inselbergs in the Brazilian Atlantic rainforest. Diversity and Distribution 4: 107-119.

Ribeiro, J.F. \& Walter, B.M.T. 1998. Fitofisionomias do bioma cerrado. Pp. 89-166. In: S.M. Sano \& S.P. Almeida (eds.). Cerrado: ambiente e flora. Planaltina, Embrapa-CPAC.

Rizzini, C.T. 1997. Tratado de Fitogeografia do Brasil: aspectos ecológicos, sociológicos e florísticos. $2^{\mathrm{a}} \mathrm{ed}$. Âmbito Cultural Edições Ltda.

Scarano, F.R. 2002. Structure, function and floristic relationships of plant communities in stressful habitats marginal to the Brazilian Atlantic Rainforest. Annals of Botany 90: 517-524.

Veloso, H.P. \& Góes-Filho, L. 1982. Fitogeografia Brasileira. Classificação Fisionômico-Ecológica da Vegetação. Bol. Téc. Projeto RADAMBRASIL. Sér. Vegetação $\mathbf{N}^{\circ} \mathbf{1}$, Salvador.

Walker, J. \& Gillison, A.N. 1982. Australian Savannas. In: B.J. Huntley \& B.H. Walker (eds.). Ecology of Tropical Savannas. Ecological Studies 42: 5-24.

Walter, H. 1971. Ecology of tropical and subtropical vegetation. Edinburgh, Oliver \& Boyd.

Walter, H. 1973. Die Vegetation der Erde. Band I: Die tropischen und subtropischen Zonen. 3. Auflage. Veb Gustav Fischer Verlag, Jena. 
Walter, H. 1986. Vegetação e Zonas Climáticas. São Paulo, E.P.U. Ltda.

Walter, H.; Harnickell, E. \& Mueller-Dombois, D. 1975. Climate-diagram Maps of the Individual Continents and the Ecological climatic Regions of the Earth. New York, Springer-Verlag.

Walter, H. \& Lieth, H. 1960. Klimadiagramm-Weltatlas. Veb. Gustav Fischer Verlag, Jena.
Watanabe, S. (coord.). 1997. Glossário de Ecologia. $2^{a}$ edição. São Paulo, Publicação ACIESP n. 103.

Weaver, J.E. \& Clements, F.E. 1938. Plant Ecology. London, McGraw-Hill Book Co.

Whittaker, R.H. 1971. Communities and Ecosystems. Fourth Printing. New York, The Macmillan Co.

Whittaker, R.H. 1978. Classification of Plant Communities. Dr. W. Junk bv Publishers, The Hague. 